\title{
Levothyroxine Treatment of Pregnant Women with Hypothyroidism: Retrospective Analysis of a US Claims Database
}

\author{
Maureen J. Lage $\cdot$ Jamie Vora $\cdot$ Zsolt Hepp $\cdot$ Ramon Espaillat
}

Received: November 12, 2019 / Published online: January 18, 2020

(C) The Author(s) 2020

\section{ABSTRACT}

Background: Approximately 2-4\% of women of reproductive age have hypothyroidism. This study characterizes pregnant women with hypothyroidism and examines adherence to guidelines during pregnancy.

Methods: Women age 18 to 49 who were pregnant in 2014 and identified with hypothyroidism $(N=3448)$ were included in the retrospective study. The analyses examined differences in characteristics and comorbidities between pregnant women treated with

Enhanced Digital Features To view enhanced digital features for this article go to https://doi.org/10.6084/ m9.figshare.11500461.

M. J. Lage

HealthMetrics Outcomes Research, LLC, Bonita Springs, FL, USA

J. Vora

Healthcare Solutions, AbbVie, Inc, North Chicago, IL, USA

Z. Hepp

Global Health Economics and Outcomes Research, Endocrinology, AbbVie, Inc, North Chicago, IL, USA

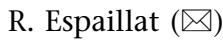

Endocrinology and Metabolic, AbbVie Inc, North

Chicago, IL, USA

e-mail: ramon.espaillat@abbvie.com levothyroxine and untreated women and adherence to guidelines by measuring thyroidstimulating hormone (TSH) target achievement for women treated with levothyroxine.

Results: The average age was 32.76 years, and the median TSH value was $1.97 \mathrm{mIU} / \mathrm{l}$. Compared with untreated pregnant women, pregnant women treated with levothyroxine were significantly younger, had a lower Charlson Comorbidity Index score and had lower rates of comorbid type 2 diabetes and migraines. Among women treated with levothyroxine, $52.61 \%$ had a last recorded TSH value consistent with American Thyroid Association (ATA) guidelines, $23.85 \%$ were undertreated, $1.03 \%$ were overtreated, and $22.52 \%$ did not have TSH monitored during their pregnancy.

Conclusions: A large percentage of pregnant women, including many treated with levothyroxine, was not treated in a manner consistent with clinical guidelines. Additionally, there were significant differences in general health and comorbidities between pregnant women treated with levothyroxine and those untreated.

Keywords: Hypothyroidism; Levothyroxine; Pregnancy; Treatment; Women 


\section{Key Summary Points}

Why carry out this study?

Hypothyroidism (HT) is a common disease in the US, more prevalent in women than men and associated with adverse maternal and fetal outcomes if left untreated during pregnancy.

Clinical guidelines recommend screening for HT among women who are pregnant or planning a pregnancy and, if diagnosed with HT, treatment with levothyroxine in consultation with an endocrinologist who monitors thyroid-stimulating hormone (TSH) levels.

This study describes treatment of pregnant women diagnosed with HT and examines the concurrence between observed TSH levels and clinical practice guidelines' recommended levels.

\section{What was learned from the study?}

Among women treated with levothyroxine, $52.61 \%$ had a last recorded TSH value consistent with American Thyroid Association (ATA) guidelines, $23.85 \%$ were undertreated, $1.03 \%$ were overtreated, and $22.52 \%$ did not have TSH monitored during their pregnancy.

A large percentage of the women, including many treated with levothyroxine, was not treated in a manner consistent with clinical guidelines.

There were significant differences in general health and comorbidities between pregnant women treated with levothyroxine and those untreated.

\section{INTRODUCTION}

Thyroid hormone deficiency, or hypothyroidism, affects $4.6 \%$ of the US population and is significantly more prevalent in women [1].
Among women of reproductive age, the rate of hypothyroidism has been estimated to be $2-4 \%$ [2]. Hypothyroidism can be difficult to diagnose in women who are pregnant, given that enlargement of the thyroid gland, increases in thyroid hormone levels, fatigue and other symptoms commonly associated with hypothyroidism are normal conditions of pregnancy [3]. However, one study found that among the $23 \%$ of pregnant women who were screened for hypothyroidism, the prevalence was $15.5 \%$ [4]. Hypothyroidism has been linked to ovulatory and menstrual dysfunction, infertility and repeated miscarriages $[2,5,6]$. In addition, if untreated during pregnancy, the condition can lead to adverse maternal and fetal outcomes, including spontaneous miscarriage, preterm delivery, preeclampsia, maternal hypertension, postpartum hemorrhage, low birth weight and still birth [7]. Research has further shown that hypothyroidism in early pregnancy may be associated with temporary and permanent intellectual and psychomotor impairment of the child. The risk of many of these maternal adverse events can be reduced, and impairment of the child might be prevented with levothyroxine treatment [8-11].

Given the impact of hypothyroidism on women of child-bearing age, pregnant women and their offspring, a wide range of clinical guidelines recommends screening for hypothyroidism among women who are pregnant or planning a pregnancy $[7,12-15]$. When a pregnant woman is diagnosed with hypothyroidism, medical guidelines recommend that she be treated with levothyroxine in consultation with an endocrinologist who monitors her thyroid-stimulating hormone (TSH) levels consistently [7]. However, studies examining frequencies of undertreatment of hypothyroidism have shown relatively large percentages of women do not achieve TSH values within recommended guidelines $[6,11,16,17]$. The present retrospective study used medical claims and laboratory data to observe and describe treatment among pregnant women identified with hypothyroidism in the US. In addition, this investigation examined the concurrence between clinical practice guidelines and TSH 
levels among the pregnant women taking levothyroxine.

\section{METHODS}

This retrospective cohort study used data spanning the years 2013 through 2015 from the Optum Clinformatics ${ }^{\mathrm{TM}}$ database, which contains information on $>150$ million individuals and laboratory results for $>30$ million people. Before release, the data were verified, adjudicated and adjusted. The databases have been used in $>90$ published research studies. The data contain information regarding patient demographics, inpatient and outpatient services, and outpatient prescription drugs. The information is fully de-identified and HIPAA compliant. Given the retrospective nature of the study design and the de-identified data, the study was exempt from internal review board evaluation.

Women ages 18-49 years who were identified as both hypothyroid and pregnant in 2014 were included in the study. Specifically, women were classified as hypothyroid if they received two or more diagnoses of hypothyroidism (ICD-9-CM of 243.xx-244.xx, except $242.2 x$ and $244.3 x$ ) or if they received one diagnosis of hypothyroidism and filled one or more prescriptions for levothyroxine. Pregnancy was identified by receipt of two or more diagnoses of pregnancy (ICD-9-CM of 63x.xx-67x.xx, V22.xx, V23.xx or V27.xx) in 2014. Given the above, pregnancy episodes were identified using a previously validated algorithm [18], and patients were excluded from the analyses if they were identified as having thyroid cancer (ICD-9-CM of 193.xx or V10.87) prior to or during their pregnancy or if they did not have continuous insurance coverage over the course of their pregnancy. Finally, every woman was required to have at least one recorded laboratory test result for any cause over the course of their pregnancy to ensure that they went to laboratories that shared test results with the database vendor. Figure 1 illustrates how each of the inclusion and exclusion criteria affected sample size.

The research characterized pregnant women with hypothyroidism and the differences

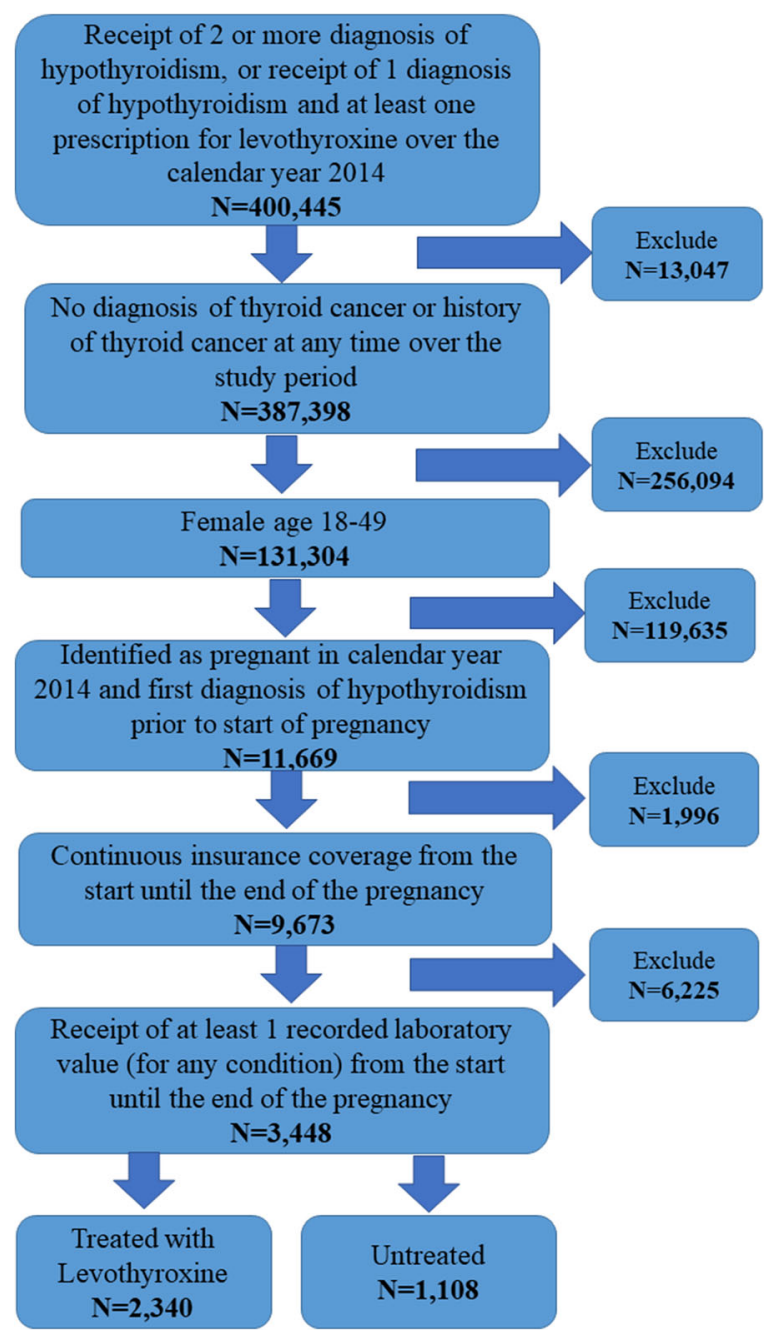

Fig. 1 Inclusion and exclusion criteria and sample size

among these individuals based upon the treatment they received. The patient characteristics of interest included age, region, type of insurance plan, diagnosing physician and general health as proxied by the Charlson Comorbidity Index (CCI) $[19,20]$. The diagnosing physician was proxied by identifying the physician type associated with the first diagnosis of hypothyroidism. The CCI is a summary measure of an individual's comorbid conditions, which is often used as a proxy measure of overall health status [21]. The analyses also examined whether the woman had a consultation with an endocrinologist during her pregnancy (denoted as 'visit endocrinologist' below) as well as the number of TSH tests and the TSH laboratory 
result(s). Finally, the analyses also examined certain comorbidities, including Addison's disease, bipolar disorder, celiac disease, chronic kidney disease, depression, dyslipidemia, heart failure, hypertension, migraine, myasthenia gravis, obesity, pernicious anemia, rheumatoid arthritis, schizophrenia, systemic lupus erythematosus, type 1 diabetes and type 2 diabetes. These comorbidities were included because they have been linked to hypothyroidism in pregnancy by either previous research [22-25] or the American Association of Clinical Endocrinologists and the American Thyroid Association (AACE/ATA) clinical practice guidelines for hypothyroidism in adults [7].

The present study also examined adherence to the 2012 AACE/ATA guidelines, which recommend that pregnant women with hypothyroidism receive treatment with levothyroxine, consult with an endocrinologist and, when treated with levothyroxine, have their TSH levels monitored. Treatment guidelines also specify target TSH levels between 0.1 and $2.5 \mathrm{mIU} / \mathrm{l}$ in the first trimester, 0.2 and $3.0 \mathrm{mIU} /$ 1 in the second trimester and 0.3 and $3.0 \mathrm{mIU} / \mathrm{l}$ in the final trimester [13]. Patients with TSH levels within the target range for their term of pregnancy were identified as appropriately treated, while those with TSH levels above or below target were identified as undertreated or overtreated, respectively. Sensitivity analyses were used to examine the robustness of the findings regarding TSH monitoring. Specifically, analyses were conducted using a 1-week earlier and 1-week later estimated pregnancy start date, requiring at least two TSH tests over the pregnancy instead of only one and establishing an upper limit TSH target of 2.5, 3.0 and $3.5 \mathrm{mIU} / \mathrm{l}$ in the first, second and third trimester of pregnancy, respectively, while removing the lower limit [7].

The analysis characterized the sample using descriptive statistics, such as mean and standard deviation or median and interquartile range for continuous variables and frequency and percentages for categorical variables. Results from the Kolmogorov-Smirnov test revealed that continuous variables (age and TSH) were not to be normally distributed. Therefore, differences in these variables were examined using Mann-
Whitney $U$ tests when examining differences across two categories and Kruskal-Wallis tests when examining differences across four categories. Differences in categorical variables were examined using chi-square tests. When tests revealed significant differences among four categories, ex post multiple pairwise comparisons were conducted using a Bonferroni adjusted $P$ value. All analyses were conducted using SAS, version 9.4.

\section{RESULTS}

A total of 3448 women ages 18-49 were identified with a diagnosis of hypothyroidism, were pregnant and met all other study inclusion and exclusion criteria. As Table 1 illustrates, the average age of these women was 33 years, and approximately two-thirds (67.9\%) were treated with levothyroxine. These women were most commonly diagnosed with hypothyroidism at an obstetrician/gynecologist's office, a general acute care hospital or an endocrinologist's office, although only $12.3 \%$ visited an endocrinologist at any time while pregnant. In its comparison of treated and untreated patients, Table 1 also reveals differences in geographical location and physician type. Patients who were treated with levothyroxine were less likely to reside in the South, more likely to reside in the Northeast or West, less likely to be diagnosed by an endocrinologist and less likely to be treated by an endocrinologist at any time during their pregnancy. The treated patients were also in better general health, as proxied by a significantly lower CCI. There was no statistically significant difference in the number of TSH tests between patients treated with levothyroxine and those untreated for their hypothyroidism. Figure 2 illustrates differences in comorbidity rates between treated and untreated patients for all of the comorbidities of interest that were diagnosed in at least $2 \%$ of the population. The pregnant women in this study were most frequently diagnosed with comorbid obesity, dyslipidemia and depression. Those who were treated with levothyroxine, compared with those untreated, were significantly less likely to 
Table 1 Patient characteristics and hypothyroidism treatment-overall and by treatment status

\begin{tabular}{|c|c|c|c|c|}
\hline Variable & $\begin{array}{l}\text { All pregnant women } \\
(N=3448) \\
N(\%) \text {, mean } \pm S D \text { or } \\
\text { median [IQ range] }\end{array}$ & $\begin{array}{l}\text { Treated with } \\
\text { levothyroxine } \\
(N=2340) \\
N(\%), \text { mean } \pm \mathrm{SD} \text { or } \\
\text { median [IQ range] }\end{array}$ & $\begin{array}{l}\text { Untreated }(N=1108) \\
N(\%), \text { mean } \pm S D \text { or } \\
\text { median [IQ range] }\end{array}$ & $P$ value \\
\hline \multicolumn{5}{|l|}{ Patient characteristics } \\
\hline Age $($ mean $\pm S D)$ & $32.76 \pm 4.80$ & $32.57 \pm 4.76$ & $33.14 \pm 4.87$ & 0.0018 \\
\hline Region $[n(\%)]$ & & & & $<0.0001$ \\
\hline Northeast & $542(15.72)$ & $371(15.85)$ & $171(15.43)$ & \\
\hline Midwest & $581(16.85)$ & $421(17.99)$ & $160(14.44)$ & \\
\hline South & $1541(44.69)$ & $976(41.71)$ & $565(50.99)$ & \\
\hline West & $781(22.65)$ & $570(24.36)$ & $211(19.04)$ & \\
\hline Other & $3(0.09)$ & $2(0.09)$ & $1(0.09)$ & \\
\hline $\begin{array}{l}\text { Insurance plan type } \\
{[n(\%)]}\end{array}$ & & & & 0.9254 \\
\hline $\begin{array}{l}\text { Exclusive provider } \\
\text { organization }\end{array}$ & $438(12.70)$ & $297(12.69)$ & $141(12.73)$ & \\
\hline $\begin{array}{l}\text { Health maintenance } \\
\text { organization }\end{array}$ & $117(3.39)$ & $77(3.29)$ & $40(3.61)$ & \\
\hline Indemnity & $1(0.03)$ & $1(0.04)$ & $0(0.00)$ & \\
\hline Point of service & $2831(82.11)$ & $1922(82.14)$ & $909(82.04)$ & \\
\hline $\begin{array}{l}\text { Preferred provider } \\
\text { organization }\end{array}$ & $61(1.77)$ & $43(1.84)$ & $18(1.62)$ & \\
\hline $\begin{array}{l}\text { Diagnosing physician } \\
{[n(\%)]^{a}}\end{array}$ & & & & $<0.0001$ \\
\hline Endocrinologist & $394(11.43)$ & $208(8.89)$ & $186(16.79)$ & \\
\hline Family medicine & $333(9.66)$ & $246(10.51)$ & $87(7.85)$ & \\
\hline Internal medicine & $239(6.93)$ & $159(6.79)$ & $80(7.22)$ & \\
\hline $\begin{array}{l}\text { Obstetrics and } \\
\text { gynecology }\end{array}$ & $483(14.01)$ & $355(15.17)$ & $128(11.55)$ & \\
\hline $\begin{array}{l}\text { General acute care } \\
\text { hospital }\end{array}$ & $575(16.68)$ & $417(17.82)$ & $158(14.26)$ & \\
\hline Other & $1424(41.30)$ & $955(40.81)$ & $469(42.33)$ & \\
\hline $\begin{array}{l}\text { Charlson comorbidity } \\
\text { Index }(\text { mean } \pm S D)\end{array}$ & $0.18 \pm 0.53$ & $0.16 \pm 0.50$ & $0.21 \pm 0.60$ & 0.0086 \\
\hline $\begin{array}{l}\text { Visit endocrinologist } \\
\quad[n(\%)]\end{array}$ & $424(12.30)$ & $227(9.70)$ & $197(17.78)$ & $<0.0001$ \\
\hline
\end{tabular}


Table 1 continued

\begin{tabular}{|c|c|c|c|c|}
\hline Variable & $\begin{array}{l}\text { All pregnant women } \\
(N=3448) \\
N(\%), \text { mean } \pm S D \text { or } \\
\text { median [IQ range] }\end{array}$ & $\begin{array}{l}\text { Treated with } \\
\text { levothyroxine } \\
(N=2340) \\
N(\%) \text {, mean } \pm \text { SD or } \\
\text { median [IQ range] }\end{array}$ & $\begin{array}{l}\text { Untreated }(N=1108) \\
N(\%), \text { mean } \pm S D \text { or } \\
\text { median [IQ range] }\end{array}$ & $P$ value \\
\hline $\begin{array}{l}\text { TSH (median [IQ } \\
\text { range]) }\end{array}$ & $1.97[1.27-3.53]$ & $1.98[1.30-3.48]$ & $1.93[1.22-3.86]$ & 0.5044 \\
\hline $\begin{array}{l}\text { No. of TSH laboratory } \\
\text { results }[n(\%)]\end{array}$ & & & & 0.1433 \\
\hline Zero & 806 (23.38) & $527(22.52)$ & $279(25.18)$ & \\
\hline One & $375(10.88)$ & $256(10.94)$ & $119(10.74)$ & \\
\hline Two-four & $1061(30.77)$ & 746 (31.88) & $315(28.43)$ & \\
\hline Five or more & $1206(34.98)$ & $811(34.66)$ & $395(35.65)$ & \\
\hline
\end{tabular}

$S D$ standard deviation, $I Q$ interquartile, $T S H$ thyroid-stimulating hormone

$T$ tests, Wilcoxon rank-sum tests and chi-square tests were used to examine differences in means, medians and proportions, respectively

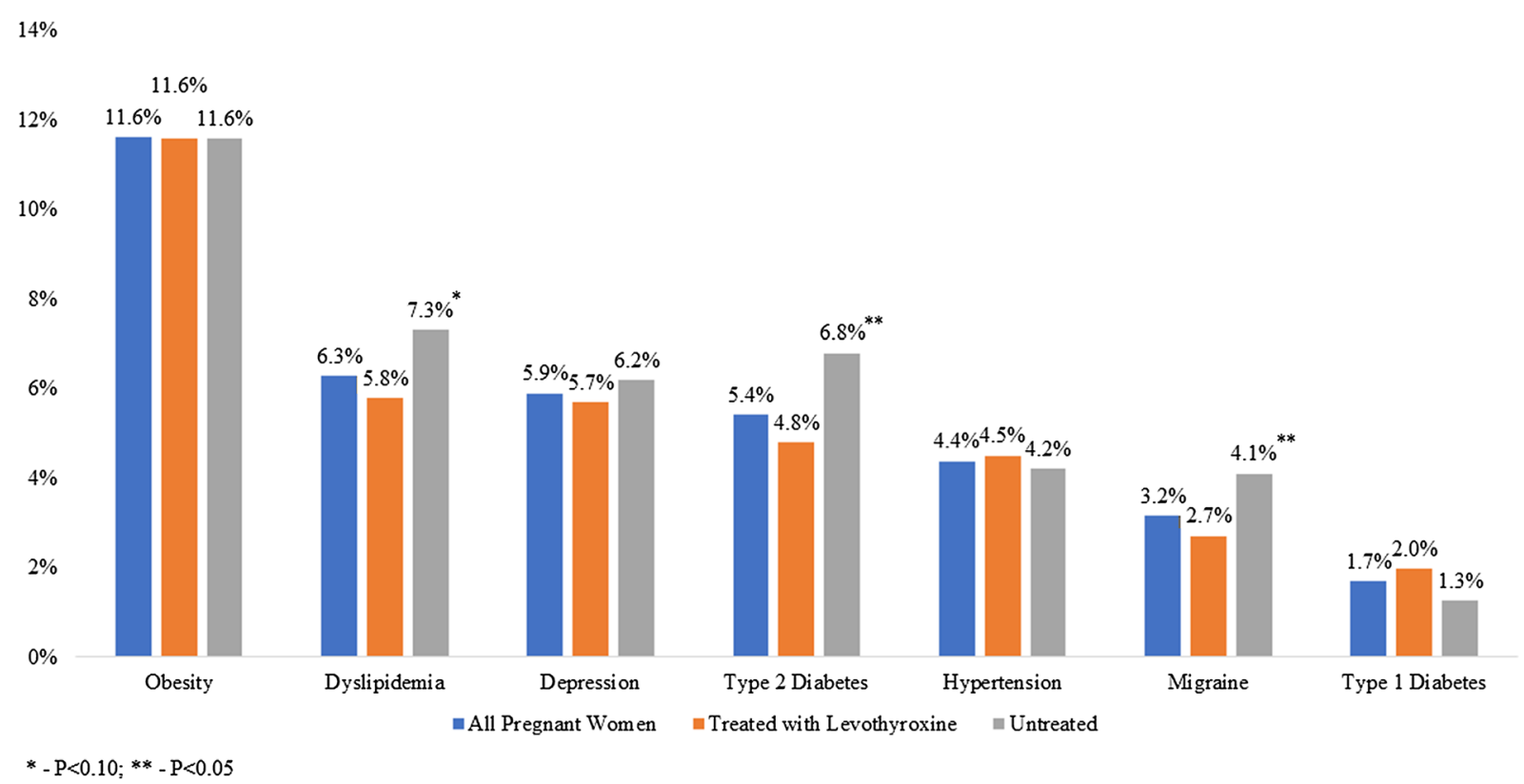

Heart failure, coronary artery disease, pernicious anemia, Addison's disease, myasthenia gravis, celiac disease, rheumatoid arthritis, systemic hpus erythematosus, bipolar disorder, and schizophrenia all appeared in less than $1 \%$ of the cohort with no statistically significant difference between treated and untreated cohorts.

Fig. 2 Comorbidities-overall and by treatment status

be diagnosed with comorbid dyslipidemia or type 2 diabetes.

Figure 3 shows whether the patient received TSH monitoring and, if so, whether the value was within the target range per ATA guidelines [13]. Slightly less than half of all patients were not monitored in accordance with guidelines during their pregnancy (47.4\%). In particular, 


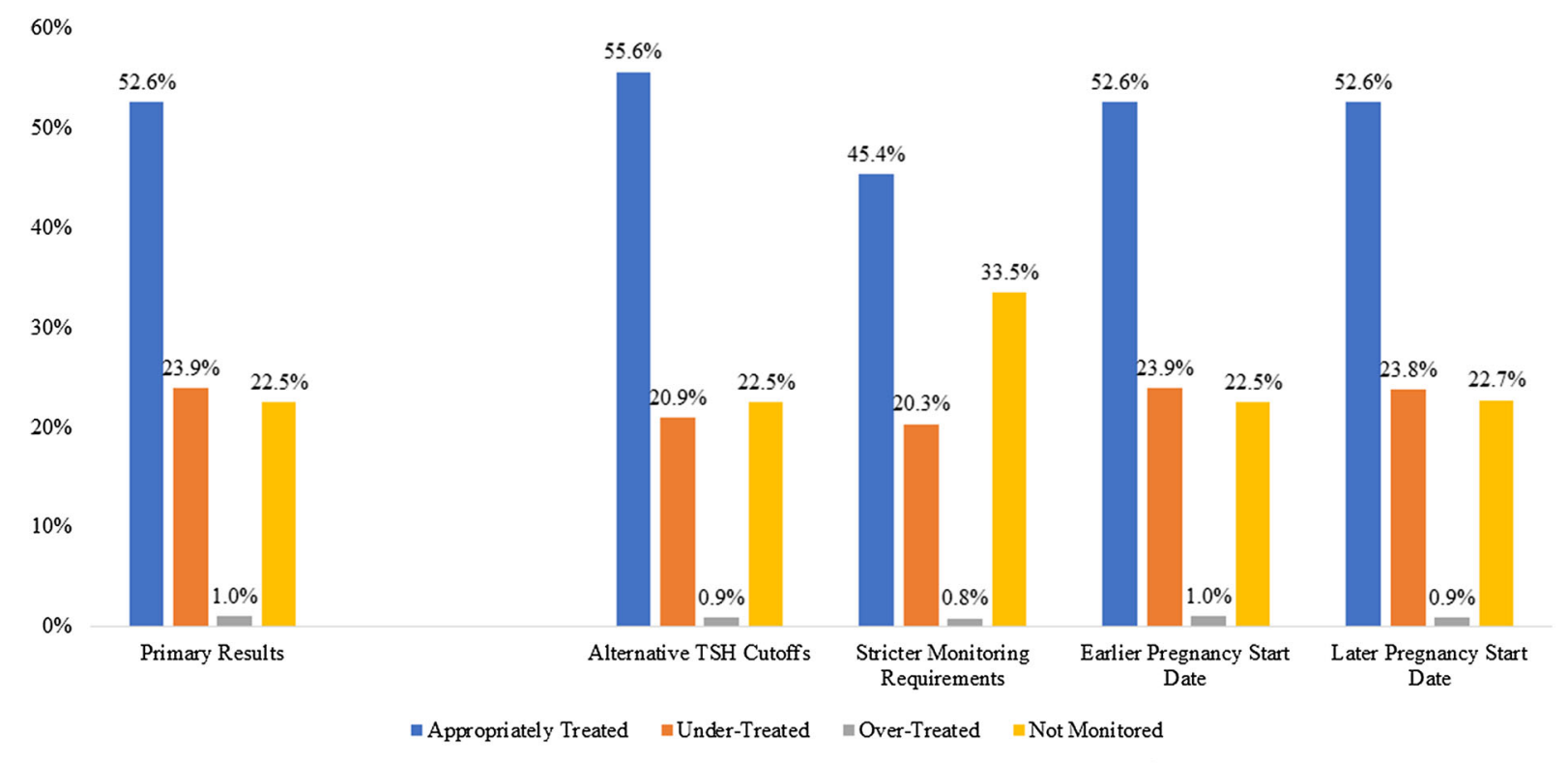

Appropriately treated, under-treated and over-treated defined as having TSH consistent with guidelines for pregnant women. ${ }^{S}$

Alternative TSH cutoffs uses alternative guidelines for defining of appropriate TSH levels; 6 Stricter monitoring requirements identified patients as monitored if they received 2 or more TSH tests during pregnancy (versus 1); Earlier and later pregnancy start date assumes the pregnancy started 7 days prior or 7 days post start date assigned using a previously validated algorithm. ${ }^{11}$

Fig. 3 TSH categories for patients treated with levothyroxine-main and sensitivity analyses

approximately one-quarter of the total population were undertreated $(23.9 \%)$ and another quarter were not monitored at all for TSH levels $(22.5 \%)$. Figure 3 also examines robustness of the results, showing that the findings were generally not sensitive to alternative specifications of pregnancy start dates or target ranges of TSH. However, patients were more likely to be identified as non-monitored (33.5\% vs. $22.5 \%)$ and less likely to be identified as appropriately treated $(45.4 \%$ vs. $55.6 \%)$ when applying the stricter requirement of at least two laboratory test results during the pregnancy.

While Table 1 compares differences between treated and untreated patients, Table 2 examines differences among treated patients based upon treatment status of undertreated, overtreated, treated appropriately or not monitored. Results reveal that those in the Northeast were least likely to be overtreated, while patients from the South were least likely to be nonmonitored. There were also statistically significant differences based upon diagnosing physician and significant differences between those patients who were not monitored and those who appropriately treated or undertreated. There were no statistically significant differences among the four groups regarding age, insurance type or CCI score.

\section{DISCUSSION}

The results of this study suggest that a significant proportion of pregnant women with hypothyroidism are not receiving the recommended care. Of the 3448 women included in these analyses, approximately one out of four never received a follow-up TSH test and another one out of four were undertreated. Nearly nine out of ten $(87.7 \%)$ did not consult with an endocrinologist, and approximately one out of three was not treated with levothyroxine. In addition, despite calls for regular monitoring of TSH levels of pregnant women who are treated with levothyroxine, there was no statistically significant difference in the number of TSH tests during pregnancy between treated and 
Table 2 Patient characteristics and hypothyroidism treatment for treated patients-by TSH treatment categories

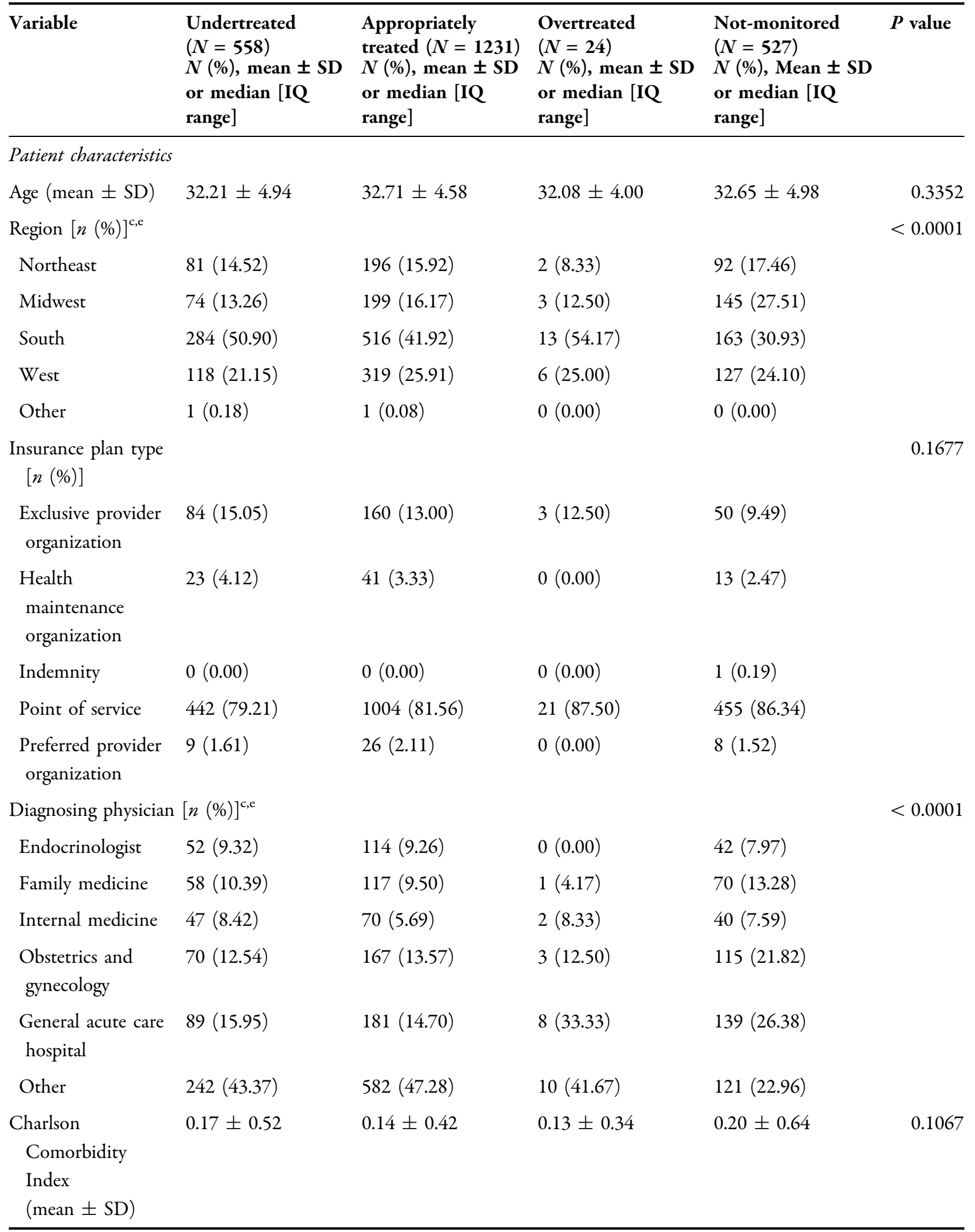


Table 2 continued

\begin{tabular}{|c|c|c|c|c|c|}
\hline Variable & $\begin{array}{l}\text { Undertreated } \\
(N=558) \\
N(\%), \text { mean } \pm \mathrm{SD} \\
\text { or median [IQ } \\
\text { range] }\end{array}$ & $\begin{array}{l}\text { Appropriately } \\
\text { treated }(N=1231) \\
N(\%), \text { mean } \pm S D \\
\text { or median [IQ } \\
\text { range] }\end{array}$ & $\begin{array}{l}\text { Overtreated } \\
(N=24) \\
N(\%), \text { mean } \pm S D \\
\text { or median }[\mathrm{IQ} \\
\text { range] }\end{array}$ & $\begin{array}{l}\text { Not-monitored } \\
(N=527) \\
N(\%), \text { Mean } \pm \text { SD } \\
\text { or median [IQ } \\
\text { range] }\end{array}$ & $P$ value \\
\hline $\begin{array}{l}\text { Visit } \\
\text { endocrinologist } \\
{[n(\%)]}\end{array}$ & $100(12.22)$ & $216(12.09)$ & $5(13.16)$ & $103(12.78)$ & 0.9652 \\
\hline $\begin{array}{l}\text { TSH (median [IQ } \\
\text { range }])\end{array}$ & $6.22[3.69-13.20]$ & $1.56[1.14-2.08]$ & $0.09[0.02-0.21]$ & $\mathrm{N} / \mathrm{A}$ & $<0.0001$ \\
\hline \multicolumn{5}{|c|}{ No. of TSH lab results $[n(\%)]^{c, e, f}$} & $<0.0001$ \\
\hline Zero & $0(0.00)$ & $0(0.00)$ & $0(0.00)$ & $527(100.00)$ & \\
\hline One & $83(14.87)$ & $168(13.65)$ & $5(20.83)$ & $0(0.00)$ & \\
\hline Two-four & $220(39.43)$ & $517(42.00)$ & $9(37.50)$ & $0(0.00)$ & \\
\hline Five or more & $255(45.70)$ & $546(44.35)$ & $10(41.67)$ & $0(0.00)$ & \\
\hline
\end{tabular}

Differences in continuous variables were examined using Kruskal-Wallis tests, and differences in categorical variables were examined using chi-square tests. For categorical variables where a statistically significant difference in groups was found $(P<0.05)$, ex post pairwise chi-square tests were conducted using a Bonferroni corrected $P$ value

$S D$ standard deviation, $I Q$ interquartile, $T S H$ thyroid-stimulating hormone

a Statistically significant difference between undertreated and appropriately treated groups

b Statistically significant difference between undertreated and overtreated groups

${ }^{c}$ Statistically significant difference between undertreated and not monitored groups

d Statistically significant difference between appropriately treated and overtreated groups

e Statistically significant difference between appropriately treated and not monitored groups

${ }^{f}$ Statistically significant difference between overtreated and not monitored groups

untreated women. The patients who were untreated were more likely to have comorbid dyslipidemia or type 2 diabetes relative to those who were treated, findings that support previous evidence that a low thyroid function has a negative effect on the lipid profile [26] and that low thyroid function leads to insulin resistance and type 2 diabetes [27]. Given this and previous evidence that appropriate treatment with levothyroxine in pregnancy can help prevent adverse outcomes $[6,7,11]$, interventions that improve the treatment of pregnant patients with hypothyroidism would likely have a significant, positive impact for payers, the health care system and society overall. However, it should also be noted that very few of the patients were found to be overtreated (1.03\%).
This finding is promising given that overtreatment has been shown to be associated with adverse skeletal events [28].

This study may underestimate the lack of adherence to guidelines. For instance, the present analyses required one or two TSH tests over the course of a pregnancy, while the current treatment guidelines recommend up to five such tests [7]. In this study only $34.98 \%$ of women received five or more TSH tests over the course of their pregnancy. Moreover, it is possible that a significant number of pregnant women with hypothyroidism were never screened and therefore never diagnosed or treated. Previous research has suggested that targeted screening of only pregnant women who are considered high-risk would miss 
$30-80 \%$ of pregnant women with hypothyroidism $[29,30]$. Universal screening of pregnant women has been shown to be costeffective [31, 32], and its implementation would be an important step toward improving pregnancy care overall.

The results of this study also revealed that treatment patterns vary by geographical region and diagnosing physician, findings that will be of interest to both payers and providers. In particular, interventions that aim to improve screening and treatment in the least compliant regions, namely, the Midwest and the South, may have a significant impact on humanistic and economic costs. In support of the recommendation that pregnant women with hypothyroidism receive monitoring from an endocrinologist [7], patients in the present study were most likely to receive monitoring and least likely to be overtreated when under an endocrinologist's care. There was no difference in median TSH among patients treated with levothyroxine and those who were identified as untreated. The reason for this finding is unknown, yet it may reflect the current complexities of treating hypothyroidism in pregnancy as well as the fact that there is no consensus on treating subclinical hypothyroidism in pregnancy [33], possibly because of the increased risk of pregnancy-related adverse outcomes offsetting risk reductions in pregnancy loss [34]. Pregnant patients with high TSH despite levothyroxine therapy may be taking too low a dose, since dose requirements increase over the course of a pregnancy [35], or some portion of patients may have treatmentrefractory hypothyroidism, which can be caused by poor adherence, interactions between the levothyroxine and food, problems with digestion or absorption, autoimmune processes or other conditions [36, 37]. The lack of monitoring found for a significant portion of our study population further complicates identification and treatment of these issues.

The results of this study should be considered in the context of the following limitations. First, the patients in this well-insured population may not be representative of all pregnant women with hypothyroidism. Second, the administrative data do not include certain types of information (e.g., diagnoses of subclinical hypothyroidism, thyroid antibody status, etc.) that may be relevant in determining outcomes. In particular, there is no guarantee that all laboratory test results were captured in the study and, further, diagnosis of hypothyroidism by code rather than serum TSH levels may have led to missing some cases. However, the results reported are generally robust to a range of sensitivity analyses around the laboratory tests. Differences in disease severity could not be assessed given the retrospective claims-based methodology, and such variations may confound findings. Furthermore, the administrative claims data may suffer from inaccurate coding. However, the data were verified, adjudicated and adjusted before release; have been used in numerous prior research projects; and allow for inclusion of a large number of patients. Third, women who received antithyroid drugs at the same time as Synthroid ${ }^{\circledR}$ and may have had hyperthyroidism were not excluded, but it is expected this would be a small number of women and results would not be affected. Fourth, the ATA updated their guidelines and expanded TSH cutoff ranges in 2017 [38]. However, the results presented in this study illustrate general patterns of treatment using guidelines that were in effect over our study period. Finally, the study is primarily descriptive in nature, and no formal hypotheses were tested.

\section{CONCLUSIONS}

In this analysis of a US nationally representative claims database, a large percentage of pregnant women with hypothyroidism was not treated in a manner consistent with clinical guidelines. Additionally, there were significant differences in general health and comorbidities between pregnant women treated with levothyroxine and those untreated. Future investigations, which may include multivariable analyses of these or similar data, into the reasons for the differences between cohorts that were observed in this descriptive study may hold answers that improve standards of care of pregnant women with hypothyroidism. 


\section{ACKNOWLEDGEMENTS}

Funding. AbbVie provided financial support for this study and the Rapid Service and Open Access Fees. AbbVie participated in the study design, research, data collection, analysis, and interpretation of data, writing, reviewing, and approving the publication. All authors had full access to all of the data in this study and take complete responsibility for the integrity of the data and accuracy of the data analysis.

Editorial Assistance. The authors would like to thank Patricia Platt and Michael Treglia for their assistance in the manuscript preparation. AbbVie provided funding for this work.

Authorship. All named authors meet the International Committee of Medical Journal Editors (ICMJE) criteria for authorship for this article, take responsibility for the integrity of the work as a whole, and have given their approval for this version to be published.

Disclosures. Drs. Ramon Espaillat and Jamie Vora are employees of AbbVie and may own AbbVie stocks or options. Zsolt Hepp was an AbbVie employee when this study was undertaken. Dr. Hepp's current affiliation is Global Health Economics and Outcomes Research, Seattle Genetics, Bothell, WA, USA. Maureen J Lage is the Managing Member of HealthMetrics Outcomes Research, which was compensated for work on this project not related to authorship.

Compliance with Ethics Guidelines. The data used in this study are fully de-identified and HIPAA compliant. Given the retrospective nature of the study design and the de-identified data, the study was exempt from internal review board evaluation.

Data Availability. Please contact the corresponding author for access to data, subject to licensing restrictions between AbbVie, Inc., and Optum.
Open Access. This article is licensed under a Creative Commons Attribution-NonCommercial 4.0 International License, which permits any non-commercial use, sharing, adaptation, distribution and reproduction in any medium or format, as long as you give appropriate credit to the original author(s) and the source, provide a link to the Creative Commons licence, and indicate if changes were made. The images or other third party material in this article are included in the article's Creative Commons licence, unless indicated otherwise in a credit line to the material. If material is not included in the article's Creative Commons licence and your intended use is not permitted by statutory regulation or exceeds the permitted use, you will need to obtain permission directly from the copyright holder. To view a copy of this licence, visit http://creativecommons.org/licenses/by$\mathrm{nc} / 4.0 /$.

\section{REFERENCES}

1. Hollowell JG, Staehling NW, Flanders WD, Hannon WH, Gunter EW, Spencer CA, Braverman LE, Serum TSH. T(4), and thyroid antibodies in the United States population (1988-1994): national Health and Nutrition Examination Survey (NHANES III). J Clin Endocrinol Metab. 2002;87:489-99.

2. Lincoln SR, Ke RW, Kutteh WH. Screening for hypothyroidism in infertile women. J Reprod Med. 1999;44:455-7.

3. National Institute of Diabetes and Digestive and Kidney Diseases 2012 Pregnancy \& Thyroid Disease | NIDDK. National Institute of Diabetes and Digestive and Kidney Diseases. Available at https://www. niddk.nih.gov/health-information/endocrine-diseas es/pregnancy-thyroid-disease. Accessed September 18, 2017.

4. Blatt AJ, Nakamoto JM, Kaufman HW. National status of testing for hypothyroidism during pregnancy and postpartum. J Clin Endocrinol Metab. 2012;97:777-84.

5. Krassas GE. Thyroid disease and female reproduction. Fertil Steril. 2000;74:1063-70.

6. Taylor P, Minassian C, Rehman A, Iqbal A, Draman M, Hamilton W, Dunlop D, Robinson A, Vaidya B, Lazarus J, Thomas S, Dayan C, Okosieme O. TSH levels and risk of miscarriage in women on long- 
term levothyroxine: a community-based study. JCEM. 2014;99:3895-902.

7. Garber JR, Cobin RH, Gharib H, Hennessey JV, Klein I, Mechanick JI, Pessah-Pollack R, Singer PA, Woeber KA, American Association of Clinical Endocrinologists and American Thyroid Association Taskforce on Hypothyroidism in Adults. Clinical practice guidelines for hypothyroidism in adults: cosponsored by the American Association of Clinical Endocrinologists and the American Thyroid Association. Endocr Pract. 2012;18:988-1028.

8. Haddow JE, Palomaki GE, Allan WC, Williams JR, Knight GJ, Gagnon J, O'Heir CE, Mitchell ML, Hermos RJ, Waisbren SE, Faix JD, Klein RZ. Maternal thyroid deficiency during pregnancy and subsequent neuropsychological development of the child. N Engl J Med. 1999;341:549-55.

9. Negro R, Formoso G, Mangieri T, Pezzarossa A, Dazzi D, Hassan H. Levothyroxine treatment in euthyroid pregnant women with autoimmune thyroid disease: effects on obstetrical complications. J Clin Endocrinol Metab. 2006;91:2587-91.

10. Kim C-H, Ahn J-W, Kang SP, Kim S-H, Chae H-D, Kang B-M. Effect of levothyroxine treatment on in vitro fertilization and pregnancy outcome in infertile women with subclinical hypothyroidism undergoing in vitro fertilization/intracytoplasmic sperm injection. Fertil Steril. 2011;95:1650-4.

11. Hallengren B, Lantz M, Andreasson B, Grennert L. Pregnant women on thyroxine substitution are often dysregulated in early pregnancy. Thyroid. 2009;19:391-4.

12. De Groot L, Abalovich M, Alexander EK, Amino N, Barbour L, Cobin RH, Eastman CJ, Lazarus JH, Luton D, Mandel SJ, Mestman J, Rovet J, Sullivan S. Management of thyroid dysfunction during pregnancy and postpartum: an Endocrine Society clinical practice guideline. J Clin Endocrinol Metab. 2012;97:2543-65.

13. Stagnaro-Green A, Abalovich M, Alexander E, Azizi F, Mestman J, Negro R, Nixon A, Pearce EN, Soldin OP, Sullivan S, Wiersinga W. Guidelines of the American Thyroid Association for the diagnosis and management of thyroid disease during pregnancy and postpartum. Thyroid. 2011;21:1081-125.

14. Reid SM, Middleton P, Cossich MC, Crowther CA, Bain E. Interventions for clinical and subclinical hypothyroidism pre-pregnancy and during pregnancy. Cochrane Database Syst Rev. 2013;5: CD7752.

15. Committee on Patient Safety and Quality Improvement, Committee on Professional Liability. ACOG Committee Opinion No. 381: subclinical hypothyroidism in pregnancy. Obstet Gynecol. 2007;110:959-60.

16. Khan I, Witczak J, Hadjieconomou S, Okosieme O. Preconception thyroid-stimulating hormone and pregnancy outcomes in women with hypothyroidism. Endocr Pract. 2013;19:656-62.

17. Vadiveloo T, Mires G, Donnan P, Leese G. Thyroid testing in pregnant women with thyroid dysfunction in Tayside, Scotland: the thyroid epidemiology, audit and research study (TEARS). Clin Endocrinol. 2013;78:466-71.

18. Hornbrook MC, Whitlock EP, Berg CJ, Callaghan WM, Bachman DJ, Gold R, Bruce FC, Dietz PM, Williams SB. Development of an algorithm to identify pregnancy episodes in an integrated health care delivery system. Health Serv Res. 2007;42: 908-27.

19. Quan H, Sundararajan V, Halfon P, Fong A, Burnand B, Luthi J-C, Saunders LD, Beck CA, Feasby TE, Ghali WA. Coding algorithms for defining comorbidities in ICD-9-CM and ICD-10 administrative data. Med Care. 2005;43:1130-9.

20. Deyo RA, Cherkin DC, Ciol MA. Adapting a clinical comorbidity index for use with ICD-9-CM administrative databases. J Clin Epidemiol. 1992;45: 613-9.

21. Baser O, Palmer L, Stephenson J. The estimation power of alternative comorbidity indices. Value Health. 2008;11:946-55.

22. Chandra A. Prevalence of hypothyroidism in patients with chronic kidney disease: a cross-sectional study from North India. Kidney Res Clin Pract. 2016;35:165-8.

23. Furukawa S, Yamamoto S, Todo $\mathrm{Y}$, Maruyama K, Miyake T, Ueda T, Niiya T, Senba T, Torisu M, Kumagi T, Miyauchi S, Sakai T, Minami H, Miyaoka H, Matsuura B, Hiasa Y, Onji M, Tanigawa T. Association between subclinical hypothyroidism and diabetic nephropathy in patients with type 2 diabetes mellitus. Endocr J. 2014;61:1011-8.

24. Radhakrishnan R, Calvin S, Singh JK, Thomas B, Srinivasan K. Thyroid dysfunction in major psychiatric disorders in a hospital based sample. Indian J Med Res. 2013;138:888-93.

25. Lisotto C, Mainardi F, Maggioni F, Zanchin G. The comorbidity between migraine and hypothyroidism. J Headache Pain. 2013;14:P138.

26. Rizos CV, Elisaf MS, Liberopoulos EN. Effects of thyroid dysfunction on lipid profile. Open Cardiovasc Med J. 2011;5:76-84. 
27. Wang C. The relationship between type 2 diabetes mellitus and related thyroid diseases. J Diabetes Res. 2013. https://doi.org/10.1155/2013/390534.

28. Chakera AJ, Pearce SH, Vaidya B. Treatment for primary hypothyroidism: current approaches and future possibilities. Drug Des Devel Ther. 2011;6: $1-11$.

29. Vaidya B, Anthony S, Bilous M, Shields B, Drury J, Hutchison S, Bilous R. Detection of thyroid dysfunction in early pregnancy: universal screening or targeted high-risk case finding? J Clin Endocrinol Metab. 2007;92:203-7.

30. Chang DLF, Leung AM, Braverman LE, Pearce EN. Thyroid testing during pregnancy at an academic Boston Area Medical Center. J Clin Endocrinol Metab. 2011;96:E1452-6.

31. Thung SF, Funai EF, Grobman WA. The cost-effectiveness of universal screening in pregnancy for subclinical hypothyroidism. Am J Obstet Gynecol. 2009;200:267.e1-7.

32. Dosiou C, Barnes J, Schwartz A, Negro R, Crapo L, Stagnaro-Green A. Cost-effectiveness of universal and risk-based screening for autoimmune thyroid disease in pregnant women. J Clin Endocrinol Metab. 2012;97:1536-46.

33. Khan I, Okosieme OE, Lazarus JH. Current challenges in the pharmacological management of thyroid dysfunction in pregnancy. Expert Rev Clin Pharmacol. 2017;10:97-109.

34. Maraka S, Mwangi R, McCoy R, Yao X, Sangaralingham L, Singh Ospina N, O'Keeffe D, De Ycaza A, Rodriguez-Gutierrez R, Coddington C, Stan M, Brito J, Montori V. Thyroid hormone treatment among pregnant women with subclinical hypothyroidism: US national assessment. BMJ. 2017;25:i6856.

35. Ramprasad M, Bhattacharyya SS, Bhattacharyya A. Thyroid disorders in pregnancy. Indian J Endocrinol Metab. 2012;16:S167-70.

36. Centanni M, Benvenga S, Sachmechi I. Diagnosis and management of treatment-refractory hypothyroidism: an expert consensus report | SpringerLink. J Endocrinol Investig 2017. Available at https://link. springer.com/article/10.1007/s40618-017-0706-y. Accessed September 12, 2017.

37. Ramadhan A, Tamilia M. Treatment-refractory hypothyroidism. CMAJ. 2012;184:205-9.

38. Alexander EK, Pearce EN, Brent GA, Brown RS, Chen $\mathrm{H}$, Dosiou C, Grobman WA, Laurberg P, Lazarus JH, Mandel SJ, Peeters RP, Sullivan S. 2017 Guidelines of the American Thyroid Association for the diagnosis and management of thyroid disease during pregnancy and the postpartum. Thyroid. 2017;27:315-89. 